\title{
Multiple agents, blame games and public policy-making: The case of local government
}

reform in New South Wales

Politicians often use 'independent experts' to avoid blame for contentious public policy. The use of multiple agents, however, has attracted relatively little attention. We extend the blameavoidance literature to identify additional opportunities and risks that arise when multiple agents are used to support/oppose particular public policies. We then test our propositions using evidence from recent local government reforms in New South Wales. The picture which emerges is largely one of confusion whereby independent agents provide contradictory opinions, attempt to shift blame to one another, and dispute interpretations of earlier advice. We conclude our analysis with a discussion of the salient factors for successful pursuit of the multiple-agent variant of the blame games.

Keywords: Blame avoidance; blame games; independent experts; multiple agents; NSW government. 


\section{Introduction}

Politicians tasked with implementing public policy are faced with two problems. First, unpopular public policy generally involves high marginal cost, given that just 'some, not all, voters need to pursue retribution as a voting objective for a politician's office to be in danger' (Weaver 1986: 378). Thus, office holders are provided with a rational choice incentive to use blame-avoidance strategies. Second, it is often difficult for politicians to know ex ante whether a public policy is likely to prove unpopular. Therefore, in most cases, the use of blame-avoidance strategies involves the potential sacrifice of political credit.

Yet some public policy reforms are almost certain to engender community angst. One such policy is the compulsory amalgamation of local governments. For instance, it has been argued that the threat of electoral backlash against the Barnett conservative government in Western Australia stalled proposed amalgamations in Perth in 2015 (Goode 2015: 71). Similarly, the forced amalgamations in Queensland, Australia in 2008 attracted voter backlash, contributing to a 15.7 per cent swing against the incumbent Bligh Labor government at the 2012 state elections, then the largest swing in Australia's political history (Grant, Dollery and Kortt 2015a: 489). Moreover, Allan (2003: 75) asserted that 'public backlash to amalgamations ... was perhaps the prime reason for the Kennett conservative government losing office' in the Victorian state election of 1999. Against this background it might seem surprising that in 2015 the NSW government embarked on a program of amalgamations aimed at reducing the number of councils in the state by over a quarter, although explanations such as financial efficiency, gerrymander, a $\$ 1.3$ billion saving over 20 years and bowing to the developer lobby have all been tendered (Drew, Grant and Campbell 2016). It is completely unsurprising, however, that NSW government politicians made efforts to insulate themselves from blame pursuant to the amalgamation program. 
Hood (2007) identified a tripartite typology of blame-avoidance strategies used by politicians: presentational strategies, policy strategies and agency strategies. For Hood (2007) presentational strategies focus on political rhetoric, timing and diversionary tactics in order to limit the damage to incumbents (see Drew et al. 2016 for a discussion of the rhetoric surrounding these council amalgamations). Policy strategies include avoiding unpopular policy (which in this case would have meant not executing forced amalgamations), failing to provide services that may attract blame and relying on policies enacted by predecessors (Hood 2007). This article focuses principally on Hood's (2007) third blame-avoidance strategy, agency approaches, but we acknowledge that there is an element of 'presentation' generally in the agency approach used by the NSW government. This is, however, quite distinct from 'presentational strategies' as conceived by Hood (2007). We suggest that, given both their prominence in explaining political behaviour and the fact that successful implementation of agency tactics can entirely eliminate the need for the other two types of blame-avoidance manoeuvres, agency strategies deserve to form the primary locus of inquiry.

The single-agent approach to avoiding blame uses an independent agent or delegated senior bureaucrat to make recommendations for contentious public policy reform, often according to carefully constructed terms of reference. The holy grail of this approach is to achieve "blame shift', whereby the delegated agent attracts the entire blame for contentious public policy reform. The consolation prize is 'blame sharing' between the principal and agent. Additionally, there is a possibility that 'blame reversion' will occur, wherein the public perceive that the delegated agent was a sham set up entirely for the purpose of blame avoidance. 
The literature has focused almost exclusively on the case of a single agent being used for blame-avoidance purposes. Yet politicians occasionally use multiple agents for purposes that may include blame avoidance and, indeed, there is evidence of increasing agencification of public policy (Mortensen 2016). For instance, in the Australian context, the NSW local government amalgamation program 'Fit for the Future' (FFTF) involved no less than six different 'independent' agents. Moreover, as we demonstrate in this context, the use of multiple agents opens up new risks and opportunities for politicians. We argue that our explication of matters arising from the use of multiple agents thus fills an important gap in the literature. It should be noted, however, that we do not assert that blame avoidance was the sole reason for the use of multiple expert agents in this particular instance: 'We are unable to get inside the minds of ministers in order to ascertain the balance between conscious deliberations, general political instincts' and genuine efforts to source expert advice for complex public policy (McConnell, Gauga and Botterill. 2008: 613). What we do assert is that the artefacts arising from the disputatious public policy under examination are consistent with, and cast light on, the proposition that use of multiple agents for blame-avoidance purposes has implications which are not considered in the blame-avoidance literature.

The particular public policy program that forms our study can be sketched thus: following an extended period of consultation and inquiry stretching back to 2011, the NSW government's reform package for local government, 'launched' in 2014 and entitled 'Fit for the Future' (OLG 2015a), required that councils demonstrate that they could meet performance benchmarks on seven metrics derived exclusively from financial data, plus a qualitative judgement concerning 'adequate scale and capacity'. Despite prima facie evidence that the program of amalgamation rested on insufficient or questionable indicators distorted by unreliable data (Drew and Dollery 2015), the government insisted that councils that failed to 
achieve 'fit' status pursue the mergers initially proposed by the Independent Local Government Review Panel (ILGRP 2013), which relied heavily on the financial sustainability assessments prepared by the NSW Treasury Corporation (TCorp 2013). The Independent Pricing and Regulatory Tribunal (IPART 2015a), with the assistance of Ernst \& Young (2015), deemed 63 per cent of NSW local governments to be 'unfit' and the far majority of these assessments failed on the 'adequate scale and capacity' criteria. Councils were required to submit details of proposed mergers to the Office of Local Government (OLG) by 18 November 2015 and the government announced amalgamation plans on 18 December 2015.

In order to explore our various propositions with respect to the use of multiple agents for blame avoidance, or what might be termed 'weapons of mass expertisation' in this particular instance of public policy, the article is divided into five sections. The next section defines key concepts and reviews the literature on agency approaches to blame avoidance. Third, we examine explanations for the use of multiple agents and discuss the possible responses specific to a multiple-agent strategy. Fourth, the article examines artefacts from the FFTF program in order to test our explanations. We conclude with a consideration of the contributions of this case study to the corpus of multiple-agent blame-avoidance literature.

\section{Theories of blame avoidance}

Blame is the attribution of perceived loss or harm to a person or entity considered to have intentionally caused the loss or harm (Malle, Guglielmo and Monroe 2014). The reasons, obligations and capacity of the agent in causing loss or harm determine the degree of blame, and presentational and policy strategies for mitigating blame tend to focus on these factors. In contrast, agency strategies for mitigating blame seek to shift the attribution of loss or harm onto delegated entities and individuals, rather than politicians (Mortensen 2013). Further, 
blame has an important temporal quality (Hood 2011): the perceived harm or loss may change over time as might the agent involved in the causal train of events. In fact, loss or harm need not have actually occurred; it is sufficient for it to be anticipated (Weaver 1986). Indeed, in the political domain blame may be apportioned to incumbents in the belief that the political opposition may have realised superior outcomes (Weaver 1986).

A large body of research suggests that most individuals tend to have a negativity bias (see, for instance, Heath, Larrick and Wu 1999). Otherwise stated, individuals are inclined to be more sensitive to losses than gains of the same magnitude. In political terms this would mean, for example, that a 1 per cent loss in opinion polls might be felt more keenly than a 1 per cent gain. This leads to the conclusion that more effort will be expended on blame avoidance than on credit claiming (Hood 2011). Indeed, "persons who have suffered losses are more likely to notice the loss, to feel aggrieved and to act on that grievance, than gainers are to act on the basis of their improved state' (Weaver 1986: 373). Moreover, the marginal costs of changes to public opinion are extremely high, and politicians can rarely be sure of the outcomes from public policy initiatives. Thus a rational choice model for political decision-making is likely to predict that politicians will be prepared to forego the credit-claiming possibilities of direct control in favour of protection from blame afforded by agency strategies (Hood 2007).

\section{Agent-centred approaches to blame avoidance}

There are three possible outcomes arising from the use of an agency approach to mitigating blame. The optimal outcome of agency strategies is to shift blame entirely onto a delegated entity or individual - the so called 'lightning rod' strategy (see, for instance, Ellis 1994). This complete shift of blame is dependent on two salient factors: the degree to which voters expect politicians to control public policy formulation, and the willingness of delegates to accept 
blame. With the advent of increased media scrutiny and diverse communication options for protecting reputation, it is probably unrealistic to expect a complete 'blame shift' to occur (Mortensen 2013). The consolation prize of 'blame sharing' is therefore a more likely proposition.

Given the high marginal cost of voters seeking retribution, any reduction in blame attribution is still worthwhile from the perspective of a politician in office (Weaver 1986). Yet politicians must use blame-avoidance strategies judiciously. For instance, blame sharing might be subject to diminishing returns - that is, the advantages of delegation will reduce according to the frequency with which the tactic is used (Hood 2002).

If 'blame shifting' is the holy grail of agency strategy and 'blame sharing' a respectable consolation prize, then 'blame reversion' must be the nightmare of every politician using blame-avoidance strategies. 'Blame reversion' may occur where (1) the public perceive that delegation is a sham designed to avoid blame, or (2) the delegate successfully passes blame back by prosecuting the case that their recommendation is the outcome of restrictive terms of reference or (3) the public perceives that the politician has manipulated the delegated agent behind the scenes (see, for instance, Grant, Ryan and Lawrie 2015b). Where blame reversion occurs it means that the agency strategy has been worse than futile, for it is quite likely that the politician will receive additional blame for trying to deflect blame in the first instance $(\operatorname{Hood} 2011)$.

If we consider instances where multiple agents are used, the possible outcomes arising from agency strategies to avoid blame are expanded somewhat. For instance, we can postulate that, in addition to 'blame shift' and 'blame sharing', the use of multiple agents also offers 
enhanced possibilities via 'blame confusion' and 'blame destruction'. The strategy of using multiple agents, however, also brings with it heightened risks for political actors.

\section{Additional opportunities and risks arising from use of multiple agents}

The use of multiple agents could be explained on the basis that it brings in additional expertise and different perspectives on public policy formulation. Yet where the expertise is subsequently discarded, or multiple experts are brought in with similar skills, this may suggest that the agents may have been engaged principally for the purpose of mitigating blame.

Weaver (1986) and Hood $(2002,2007,2011)$ have both alluded to the usefulness of engaging multiple experts in order to diffuse blame. Weaver (1986:388) referred to the practice as 'circling the wagons' whilst Hood (2011) described the behaviour as a 'herding instinct' both descriptions convey an air of desperate predicament (see Drew et al. 2016). The suggestion appears to be that a fixed quantum of blame distributed between multiple agents results in smaller portions of shared blame for each agent - a 'safety in numbers' argument. Still other compelling reasons for using multiple agents can also be discerned, as we now discuss.

\section{Blame confusion}

Blame confusion works on two important components of blame: agency and time. If a succession of different agents are engaged for public policy formulation over discrete periods of time, the result may well be a moving target 'that deprives all but the most determined of their blame quarry' (Hood 2011: 81). In addition, each delegated agent is presented with the opportunity to cast blame on other agents for adverse outcomes. Successive agents can cast 
blame downwards by claiming that they are merely following the direction and recommendations set out by predecessors, whilst earlier agents can counter-claim that their work has been misrepresented. Critically, as long as agents are intent on shifting portions of blame to one another, the (theoretically) accountable politician can largely escape scrutiny. Moreover, a convoluted dialogue of this type will prove difficult for the 'sound bite' media to follow and may result in less media scrutiny for the specific public policy reform. Thus, blame confusion might be defined as the situation in which citizens find it difficult to attribute blame, owing to problems in determining which agent was responsible for what part of the public policy at any given time.

\section{Blame destruction}

Under this line of reasoning, multiple agents might be deployed to project the image that the weight of expert opinion is in favour of the proposed public policy reform and that politicians have studiously sought the best available evidence as part of a comprehensive consultation process. If sufficient numbers of high-profile experts can be engaged on the project, then this may dissuade potential dissenters from investigating the matter. After all, if it appears that a number of experts have contributed to policy formulation then it is hardly likely to be flawed.

Key to this strategy is the 'expert brand'. Therefore, a politician seeking to use multiple agents will endeavour to enlist agents with the salutation of 'professor' and agencies well regarded in their field of expertise. It is also important for voters to perceive that the agents have made their recommendations without interference from the relevant politician. Hence, agents with the keyword 'independent' are likely to feature in the blame-destruction approach (e.g., Grant et al. 2015b). In essence, reliance on an expert brand is argumentum ad verecundian (an appeal to authority). 
Under this line of reasoning, should the strategy fail to eliminate dissention entirely, it might still serve a useful purpose for the blame-avoidance objective. The fact that a number of prominent experts support the public policy means that dissenting parties must face the additional challenge of justifying their position in the face of apparent overwhelming support for the policy. It is entirely possible that dissenters will struggle to gain credibility if prominent 'expert' brands are paraded behind the policy. Therefore, even when the objective of blame destruction has not been achieved, the consolation prize may be muted dissention.

Thus blame destruction differs from extant blame-shift explanations of behaviour by focussing on the persuasive power of multiple-expert brands. It is not so much about shifting blame, but rather convincing citizens that the weight of expert opinion supports the public policy, therefore suggesting little cause for attributing blame (to anyone).

\section{Risks in deploying multiple agents}

There are also a number of risks in using multiple agents (in addition to blame reversion, as discussed earlier in the article). First, if individual agents become passionate in their attempt to deflect blame, consistent with Moynihan's (2012: 571) observation that agents are 'governed by concern for [their external] reputation', there is a real risk that the whole project could descend into a chaotic brawl. Should this occur, the public response may be to transfer blame back to the politician accountable for overseeing the process. Second, if 'expert brands' do not carry out their roles in an expert fashion, then an accusation could be made that the experts were simply guns for hire, and blame destruction may fail to occur. Attention may then fall on the cost of engaging multiple agents, particularly where agents exercise apparently similar functions. Finally, if execution of the public policy requires legislation or 
ministerial proclamation, then the deployment of multiple agents may simply delay the attribution of blame rather than avoid same.

Given the additional downside risks associated with multiple agents, one might question why a politician would use such an approach. One simple response is that politicians are imbued with a disproportionate sense of confidence in their ability to manage agents, media and the wider public. An alternative response is derived from Tversky and Kahneman's (1992) prospect theory, which posits inter alia that, when faced with a high-risk prospect, individuals will tend to be risk-seeking (see Heath et al. 1999 for experimental research). As noted earlier, forced municipal amalgamations are established as a high-probability risk prospect in the Australian political milieu. Thus, the acceptance of additional risks can be understood with reference to prospect theory. We now consider the multiple agents deployed as part of the NSW municipal amalgamation program in order to explicate our theoretical insights.

\section{Multiple-agent artefacts}

To date, six agencies have been involved with the FFTF program. Figure 1 details the chronology of the municipal reform program from August 2011 through to December 2015, with the curved arrows depicting attempts of the various agents to cast blame forward or backwards during the four years. As one will likely note, there is every indication that the various agents were far from passive recipients of blame. We review the contribution of each agency with emphasis on the risks and opportunities specific to a multiple-agent approach to blame avoidance. Representative artefacts were selected from a comprehensive review of all the materials associated with the program. We concentrated on 'direct citations and inclusion of a very broad selection of statements [which] reduces systematic bias' (Mortensen 2016: 7). Moreover, we relied on overall academic integrity which we believe is equally efficacious 
when compared with popular alternatives such as systematic coding that rely on a myriad of subjective 'judgements about how to code text' (McConnell et al. 2008; Moynihan 2012: $575)$.

\section{[PLEASE INSERT FIGURE 1 ABOUT HERE]}

\section{Independent Local Government Review Panel (ILGRP)}

FFTF had its genesis in a rather innocuous forum comprising councillors, academics and state government officials billed as 'Destination 2036' and held in August 2011. It was described as a collaborative enterprise 'reflect[ing] the NSW Government's commitment to work constructively with local government' (Elton Consulting 2011: 3). One output from the forum was a comforting and aspirational 'Vision Statement' which promised inter alia 'strong communities through partnership ... led and served by strong, effective and democratically elected local government' (Destination 2036 Implementation Steering Committee 2012: 8). A second output was the establishment of the ILGRP to 'draw on independent expertise' to 'identify how councils can best govern and be structured to support the wellbeing and prosperity of NSW communities' (Destination 2036 Implementation Steering Committee 2012: 4).

From the outset, the government emphasised the 'expert brand' of the ILGRP. For instance, the media release announcing the formation of the Panel referred to it as 'independent' and 'expert,' noting twice that a 'professor' was the chair and that Sansom 'currently heads up the Australian Centre for Excellence in Local Government' (Page 2012a). The other two Panel members were also presented as 'fellow local government experts' (Page 2012a) with extensive local government experience. Later references to the Panel's work studiously 
included references to 'independence', 'expertise' and the leadership of Sansom (e.g., Page 2012a; 2012b; 2013).

The Panel produced several reports, then a 'Final Report' detailing 65 recommendations which included 'structural reform - including council amalgamations - [as] another essential component of reform' (ILGRP 2013: 15). Yet the Panel produced no empirical evidence to support its recommendations, and academics and opposition politicians were quick to pounce on this oversight (Drew and Dollery 2015; GPSC 2015). Notwithstanding the absence of empirical support, the Panel produced a list of 'options for amalgamation' that formed the bulk of the report. It is therefore surprising that Sansom later published claims that academics had misrepresented the Panel's options for amalgamations as 'merger recommendations' (Sansom 2015b). Later still, Sansom (2015a: 3) levelled the same charge at the Independent Pricing and Regulatory Tribunal (IPART; discussed below) noting that:

in its final report, the Panel did indeed put forward a number of 'Preferred Options' for mergers, but in every case it offered an alternative in case subsequent detailed examination of the merger proposal (or Government policy) pointed in a different direction.

Sansom also criticised FFTF implementation, asserting that 'the ILGRP's broader package has been somewhat overshadowed by FFTF's perceived focus on financial ratios and benchmarks' (Sansom 2015b: 1). These seem to be salient examples of a delegate's attempts to shift blame. Notably, Sansom sought to shift blame to another delegated agent in addition to attempting blame reversion (Davies 2015). Yet the media largely failed to pick up on the story and the government continues to claim that FFTF represents its response to the findings of a comprehensive review of local government, replete with a hyperlink to the still-active 
ILGRP website (OLG 2015a). The Hansard record states that the ILGRP cost \$1.8 million (State Parliament of NSW 2015: 9).

\section{New South Wales Treasury Corporation (TCorp)}

TCorp also played a delegated role in the formulation of the FFTF public policy reform. TCorp was commissioned by the then Division of Local Government to review the financial sustainability of all NSW councils (TCorp 2013). Later the DLG 'expanded the scope of TCorp's reports to incorporate additional material to facilitate use by the Review Panel [ILGRP], particularly in respect of the area of financial sustainability' (TCorp 2013: 5). The task involved establishing a definition of financial sustainability, collecting data and constructing 10 financial ratios, establishing benchmarks for the ratios and weighting the ratio performance of each council in order to produce a financial sustainability rating on a continuum, ranging from 'distressed' through to 'very strong'. Yet the TCorp methodology appears to have lacked transparency, as well as omitting relevant metrics testified to in the literature, and this attracted some criticism (Drew and Dollery 2014). Despite these apparent problems, the ILGRP (2013: 4) relied heavily on the work of TCorp as justification for radical reforms, stating that: 'The recently released report of the NSW Treasury Corporation (TCorp) paints a disturbing picture of a local government system facing major financial problems with apparently little awareness of just how serious the situation has become'.

The NSW government emphasised the 'expert brand' of TCorp, noting that it 'is the central borrowing authority for the State of NSW' and that it 'is a manager of asset and liability portfolios on behalf of clients, providing financial risk management and investment management services to the NSW Government and its constituent businesses' (OLG 2015b). The price of the 'expert brand' of TCorp was \$2.512 million (State Parliament of NSW 2015: 
10). It is therefore somewhat surprising that the OLG (on the advice of IPART 2014) subsequently discarded most of the financial ratios in formulating the FFTF criteria (just 5 of the 10 financial ratios were used by the OLG). TCorp (2015: 1) appeared to express frustration at this turn of events, noting that it 'has been working on the assessment of local government sustainability since 2011' and criticising the subsequent agent (IPART) methodology for assessing council 'fitness' as 'not consistent with the guidance material provided to councils and their representatives'. Moreover, TCorp (2015) criticised the dichotomous financial sustainability assessment process subsequently used by IPART (in preference to the earlier work of TCorp), remarking that failure to meet the benchmark for one ratio 'does not in itself, make them [councils] unsustainable' (TCorp 2015: 3). It is noteworthy that TCorp chose to blame IPART for a poor application of its earlier work, rather than the OLG or the Minister for Local Government.

\section{Office of Local Government (OLG)}

The OLG played a pivotal role in the FFTF program. As the Minister for Local Government's department, the OLG set the strategic framework for reform (GPSC 2015). This included providing advice to the Minister on the metrics used to assess municipal 'fitness', developing the council FFTF templates and self-assessment tools, delivering FFTF marketing material and developing the council 'response to IPART assessment' templates (GPSC 2015: 11). The OLG itself was re-branded (formerly known as the Department of Premier \& Cabinet,

Division of Local Government) prior to the launch of FFTF to signify 'that the organisation is now a stand-alone agency' (State Government of NSW 2015: 11).

The OLG came in for criticism in an Upper House Inquiry into FFTF, particularly in relation to the apparently flawed metrics used in the public policy reform (GPSC 2015). In response, 
the OLG explained that the criteria were 'developed based on the recommendations and work of the NSW Treasury Corporation, the Independent Panel and the Infrastructure Audit, and were reviewed by IPART prior to finalisation' (GPSC 2015: 19). In so doing, the OLG appear to have sought to shift the blame to other delegated agents involved in the public policy reform. Moreover, the Chief Executive of the OLG, Marcia Doheny, received a harsh media response to her evidence, with particular emphasis placed on her 'embarrassing backdown when conceding she did not know what impact council mergers would have on rates' (McKenny 2015). A short media release was later issued by the Minister explaining that Doheny 'would leave the organisation for personal reasons' (Toole 2015a) just five months after taking up the position. Notably blame appears to have been shifted onto an individual within the organisation who was not used by the OLG at the time that FFTF was rolled out.

Independent Pricing and Regulatory Tribunal (IPART)

IPART had two key roles in the development of FFTF. In September 2014, it produced a report for the Premier of NSW - Review of Criteria for Fit for the Future - which provided advice on which metrics should be used to determine whether councils were 'fit'. Notably, IPART (2014:5) advised the Premier to set a benchmark for the asset maintenance ratio at 'greater than 1', introduce a debt service ratio of 'greater than $0 \%$ and less than or equal to $20 \%$ ' and endorsed 'opex per head' as a measure of efficiency. All these recommendations came in for sustained criticism in the Upper House inquiry (GPSC 2015). IPART later clarified its position on the asset maintenance and debt ratios less than a month out from the FFTF submission date (GPSC 2015: 86), prompting one seasoned observer to 'suggest that IPART was neither expert nor independent' (GPSC 2015: 26). 
IPART's second role in the FFTF program was its appointment, along with 'South Australian local government expert John Comrie, [to] act as the Expert Advisory Panel to review local councils FFTF submissions' (Toole 2015b: 1). In announcing the appointment, Toole said that 'IPART has extensive local government expertise and proven experience' and that 'councils and communities deserve these proposals to be assessed with consistency, fairness and impartiality' (Toole 2015b: 1). Once again, the media release seems to have emphasised the 'expert brand'.

The principal role of the Expert Advisory Panel was to determine whether each council was 'fit' or 'unfit' according to what has been widely regarded as an ill-defined scale and capacity criteria, along with seven metrics constructed from the financial statements. Yet before the determinations had commenced IPART (2015b: 73) was at pains to distance itself from the criteria used for FFTF, stating no less than 20 times in its assessment methodology report words to the effect that 'the benchmarks and measures have been established by the Government and although we received suggestions to alter some of these in our consultation process, it is not our role to reconsider or change them' (emphasis added). Moreover, IPART (2015b: 10) noted no less than 10 times that they had been engaged only to make assessments of a council's fitness and that the question of forced amalgamation would be 'a matter for the Government'.

IPART appears to have sought to ensure that other delegated agents would receive a portion of any blame accruing as a result of forced amalgamation decisions. For instance, IPART (2015a: 1) noted that the criteria were 'developed by the Government based on the work of Destination 2036, the assessments of the sector by the ILGRP and the NSW Treasury Corporation (TCorp), as well as input from the local government sector and IPART', in 
response to criticisms raised about IPART's involvement in developing the apparently flawed assessment metrics. Moreover, in its 'Final Report' IPART (2015a) made a number of references to the ILGRP 'merger recommendations' which it used as the basis for establishing the 'adequate scale and capacity' criteria. Indeed, IPART reproduced large sections of the ILGRP report so that there could be no doubt about the source of the merger recommendations (e.g., IPART 2015a: 44-9). The cost of the IPART work has not been publicly disclosed.

Thus it is clear that the actions of IPART are consistent with an organisation desirous to ensure that any blame associated with FFTF would be shared between the government and all delegated agents. IPART also delegated work to Ernst \& Young, to either address gaps in the Expert Advisory Panel expertise or attempt to shift blame to another agent. Given the Minister's statement (Toole 2015b: 1) that IPART 'was appointed after careful consideration' of its 'extensive local government expertise', it is not unreasonable to suggest the latter explanation might be the case.

Ernst \& Young (EY)

Ernst \& Young is one of the 'Big Four' accounting firms in the world and is thus a prominent 'expert brand'. The EY report, Fit for the future: Review of business case estimates of merger net benefits for Sydney metropolitan councils, clearly marked 'confidential', is included as an addendum to the IPART fitness assessment report. Indeed, EY (2015: 74) specifically notes that 'if IPART wishes to provide a third party with copies of the Report, then our prior written consent must be obtained'. It is important to note that the involvement of EY was not part of the Expert Advisory Panel announcements and we can find no public announcement of their engagement by the Panel. 
The EY report is replete with caveats and apparent blame-shifting devices. For instance, EY made reference to 'information and time constraints' which they cited as reason for not conducting a 'detailed deep "bottom up" review of the costs, benefits and risks of a merger' as would be done in the case of commercial transactions (EY 2015: 3). Moreover, EY noted that 'we have not independently verified, or accept any responsibility for independently verifying any information provided to us by IPART or information obtained in the public domain for the purposes of this review, nor do we make any representation as to the accuracy or completeness of the information' (EY 2015: 4). EY also stated that 'all the information we have received is the responsibility of IPART and the relevant councils' and that 'underlying assumptions and projections contained with this Report are subject to significant uncertainties and contingencies often outside the control of EY' (EY 2015: 16).

It thus appears that EY invested some effort into articulating caveats in order to escape potential blame. The cost of this 'expert branding' has not been publicly disclosed.

$K P M G$

When the NSW government (2015b) announced which councils would be amalgamated, it detailed precise estimates of the 'total financial benefits over 20 years' for each of the proposed amalgamations. This information was presented on a dedicated 'council boundary review' website (NSW government 2015a) along with a prominent declaration that the benefits were 'informed by four years of extensive council and community consultation, supported by independent analysis and modelling by KPMG' (NSW government 2015a). In addition, a report dated December 2015 - Local government reform merger impacts and analysis - and 
promptly uploaded to the website asserts inter alia a three-year payback period for merger costs, \$100 million annual total financial benefit for affected councils, and a $\$ 1.3$ billion nett financial saving over 20 years (KPMG 2015: 2). The report contains no information regarding the assumptions used in the modelling, and states that 'Its preparation has relied upon information sourced from annual data returns and long term financial plans of individual councils and a variety of other publicly available sources. Neither KPMG nor the NSW Government has independently verified such information' (KPMG 2015: 2).

Immediately calls were made for details of the assumptions underpinning the modelling of purported benefits arising from each of the amalgamation proposals. A number of councils and politicians lodged applications under the Government Information (Public Access) Act (GIPA) (2009) (e.g., NSW Government Department of Premier \& Cabinet, 2016). In January 2016, KPMG's report for the state government about financial modelling for local government mergers was released (KPMG 2016). Reaction to a number of perceived flaws in the report was swift. Specifically, the KPMG report was criticised for: (1) using the incorrect industrial award to calculate redundancy costs, (2) using assumptions inconsistent with other KPMG reports, ${ }^{1}(3)$ entirely overlooking the considerable expense associated with service harmonisation $^{2}$ and (4) making assumptions without evidential foundation. ${ }^{3}$ These prima facie damaging critiques of the report remain unanswered by the government and KPMG. Individual modelling for various amalgamation proposals has not been released: the GIPA

\footnotetext{
${ }^{1}$ For instance, the KPMG report assumes savings from efficiency in delivering materials and contracts for rural councils in the order of 2 per cent. Yet in a report produced eight months earlier for a rural council KPMG assumed this saving to be 1.5 per cent (Dollery 2016).

${ }^{2}$ When two councils amalgamate, differences in service quantity and quality must be ameliorated. Generally, 'service harmonisation' occurs at the highest level of services previously enjoyed by the residents of constituent municipalities (Steiner 2003).

${ }^{3}$ Evidence arising from the 2008 Queensland amalgamations contradicted the KPMG assumptions relating to reduced employee expenditure.
} 
determination states that the documents are 'cabinet documents' and 'that there is an overriding public interest against disclosure of the information and access to the information is refused' (NSW Government Department of Premier \& Cabinet 2016). The KPMG independent modelling cost $\$ 400,000$ (Robertson 2016).

\section{Effects of the multiple-agent approach}

The artefacts detailed above could be used for prosecuting the case that multiple agents were used for blame-avoidance purposes. This reading of events finds support from: (1) the commissioning of multiple agents with overlapping expertise (for example, EY, TCorp and KPMG), (2) the discarding of expert outputs (for instance, the omission of half of TCorp's financial sustainability ratios in council assessments) and (3) the care taken to establish independent expert brands.

Our analysis has gone well beyond the scant literature on multiple-agency approaches for blame avoidance, which has hitherto focussed on blame sharing and observed that higher numbers of agents present a higher risk of blame being cast between agents. By focussing on two explanations for deploying multiple agents - blame confusion and blame destruction within a single case study, we have identified the salient factors necessary for the successful pursuit of the multiple-agent variant of the blame games.

First, we have shown that those who might choose to use multiple agents to pursue contentious public policy have no reason to believe that the agents will be passive recipients of blame. As Figure 1 attests, all six agents were prepared to pass blame to other agents. This is consistent with the hypothesis in the literature that a 'slew of different organisations offer each player the opportunity to blame the others for failure' (Hood 2011: 68). 
Our case study, however, suggests a departure from the findings of earlier research. For instance, Moynihan (2012) suggested that the likelihood of an agent attempting to blame others is positively associated with the proportion of resources which an agent derives from external parties. If this were the case then we might have expected EY and KPMG to have been most active in attempting to shift blame to other agents. Yet blame cast by these two agents was muted. Instead EY and KPMG focussed on stating caveats to the effect that: (1) they did 'not verify or accept responsibility for independently verifying any information provided to us' (EY 2015: 4) and (2) the modelling of financial benefits from amalgamation was consistent with the finding of other agents (KPMG 2015).

Possible explanations for this behaviour include the chronology of the agents' engagement (having been engaged towards the end of the process the agents were not in a position to cast much blame upwards), and the possibility that a professional code of ethics made the agents reluctant to participate in a public bun fight (professionals such as accountants and medical practitioners tend to avoid disputes in the media). It is also possible that these particular agents did not regard it as a worthy use of their time to further deflect blame. These observations present fruitful avenues for further research.

The second major finding is that efforts to engage and promote prominent expert brands are largely undermined if the experts fail to act in an expert fashion. In our case study, the most prominent failure probably belongs to KPMG, which produced a report 'replete with ... errors of logic, gross oversimplifications and mistakes' (Dollery 2016). This assessment was picked up by a number of media outlets and this largely undermined the blame-destruction objective. Where this study breaks new ground is in identifying the importance of alternative 
expert brands in neutralising blame destruction. As noted earlier, the use of multiple expert agents means that potential dissenters face an additional challenge of justifying their position in the face of apparent overwhelming support. Our case study emphasises that 'expert brands' are thus equally important for those wishing to dispute public policy.

Notably, in our case study blame confusion failed to set in, and this finding seems to be in contrast to the contention that a succession of multiple agents engaged over discrete periods of time will present a moving target 'that deprives all but the most determined of their blame quarry' (Hood 2011: 81). For instance, the announcement of the final forced amalgamations was met with headlines clearly attributing the action to the state government:

- NSW councils to merge under State Government plan for forced amalgamations: 2016 elections delayed (ABC 2015; emphasis added);

- Bulldozed: Mike Baird to force Sydney councils to merge, Sydney Morning Herald (Davies and McKenny 2015; emphasis added).

Part of the reason for this failure to deprive the media of its blame quarry might well be the rigorous interrogation of consultant outputs by determined academics (highlighting the importance of independent academic scrutiny of public policy). Alternatively, it might be conjectured that the media is far more tenacious than previously considered in the literature.

A third explanation may be the salience of the mechanism required to effect the public policy decision. Under $\S 218 \mathrm{~F}$ of the Local Government Act (1993), the Minister must recommend the amalgamation to the Governor before the proclamation of the new entity can be made. 
Thus, in instances such as this, where the government is required to trigger the public policy recommendation, it seems that this act might refocus the media's attention on the government's ultimate responsibility for the public policy change. Future comparative studies might investigate the importance of legislative triggers in pursuing blame-confusion strategies.

Finally, our case study illustrates that blame destruction and blame confusion are in no way mutually exclusive. Neither mechanism proved to be wholly successful in the final analysis, but this was largely due to the problems outlined above (experts not acting in an expert fashion, presence of vocal alternative expert brands, tenacity of media and scholars, and the salience of the legislative trigger). In particular, it seems that, had the experts conducted themselves in an expert fashion, there would have been little for vocal alternative expert brands to criticise and hence attract little interest from the media. We conclude that politicians can use weapons of mass expertisation for both blame-confusion and blamedestruction, but they must use these mechanisms carefully if they are to be effective.

\section{References}

ABC [Australian Broadcasting Corporation]. 2015. NSW councils to merge under state government plan for forced amalgamations; 2016 elections delayed. $A B C 17$ December. URL: <http://www.abc.net.au/news/2015-12-18/sydney-councils-to-be-forced-tomerge-by-nsw-government/7039326>. Consulted 29 August 2016.

Allan, P. 2003. Why smaller councils make sense. Australian Journal of Public Administration 62(3): 74-81.

Davies, A. 2015. Graham Sansom, author of council reform, criticises government, IPART. Sydney Morning Herald 2 June. URL: <http://www.smh.com.au/nsw/graham-sansom- 
author-of-council-reform-criticises-government-ipart-20150602-ghex4j.html>. Consulted 13 August 2016.

Davies, A. and McKenny, L. 2015. Bulldozed: Mike Baird to force Sydney councils to merge. Sydney Morning Herald 18 December. URL: <http://www.smh.com.au/nsw/bulldozed-mike-baird-to-force-sydney-councils-intomergers-20151217-glpw1c.html>. Consulted 13 August 2016.

Destination 2036 Steering Committee. 2012. Destination 2036 - a path together action plan. Sydney: Destination 2036.

Dollery, B. 2016. Council amalgamation report ignores what it wants to ignore. Sydney Morning Herald 26 January. URL: <http://www.smh.com.au/nsw/councilamalgamation-report-ignores-what-it-wants-to-ignore-20160125-gmdadu.html> . Consulted 13 August 2016.

Drew, J. and Dollery, B. 2014. Estimating the impact of the proposed Greater Sydney Metropolitan amalgamations on municipal financial sustainability. Public Money \& Management 34(4): 281-8.

Drew, J. and Dollery, B. 2015. Less haste more speed: The Fit for Future reform program in New South Wales local government. Australian Journal of Public Administration 75(1): 78-88.

Drew, J., Grant, B. and Campbell, N. 2016. Progressive and reactionary rhetoric in the municipal reform debate in New South Wales (NSW) Australia. Australian Journal of Political Science 51: 323-37.

Ellis, R. 1994. Presidential lightning rods: The politics of blame avoidance. Lawrence: University Press of Kansas.

Elton Consulting. 2011. Our communities, councils, future. Sydney: Elton Consulting. 
EY [Ernst \& Young]. 2015. Fit for the future: Review of business case estimates of merger net benefits for Sydney metropolitan councils. Sydney: KPMG.

Goode, S. 2015. Amalgamation in Greater Perth. In B.E. Dollery and I. Tiley, eds. Perspectives on Australian local government reform. Sydney: The Federation Press. GPSC [General Purpose Standing Committee No. 6, NSW Legislative Council]. 2015. Local government in New South Wales. Sydney: NSW Legislative Council.

Grant, B., Dollery, B. and Kortt, M. 2015a. Is there a case for mandating directly elected 'semi-executive' mayors in Australian local government? Lessons from the 2012 Queensland local government elections. Australian Journal of Public Administration 74(4): 484-94.

Grant, B., Ryan, R. and Lawrie, A. 2015b. Dirty hands and commissions of inquiry: An examination of the NSW Independent Local Government Review Panel in NSW, Australia. Research in Ethical Issues in Organisations 13: 19-39.

Heath, C., Larrick, R. and Wu, G. 1999. Goals as reference points. Cognitive Psychology 38: 79-109.

Hood, C. 2002. The risk game and blame game. Government and Opposition 37(1): 15-37.

Hood, C. 2007. What happens when transparency meets blame-avoidance? Public Management Review 9(2): 191-210.

Hood, C. 2011. The blame game: Spin, bureaucracy and self-preservation in government. Princeton: Princeton University Press.

ILGRP [Independent Local Government Review Panel]. 2013. Revitalising local government: Final report of the NSW Independent Local Government Review Panel. Sydney: ILGRP.

IPART [Independent Pricing and Regulatory Authority]. 2014. Review of criteria for Fit for the Future local government final report September 2014. Sydney: IPART. 
IPART [Independent Pricing and Regulatory Authority]. 2015a. Assessment of council Fit for the Future proposals. Sydney: IPART.

IPART [Independent Pricing and Regulatory Authority]. 2015b. Methodology for assessment of council Fit for the Future proposals. Sydney: IPART.

KPMG. 2015. Local government reform: Merger impacts and analysis. Sydney: KPMG.

KPMG. 2016. Outline of financial modelling assumptions for local government merger proposals. Sydney: KPMG.

Malle, B., Guglielmo, S. and Monroe, A. 2014. A theory of blame. Psychological Inquiry 25(2): $147-86$.

McConnell, A., Gauja, A. and Botterill, L. 2008. Policy fiascos, blame management and AWB Limited: The Howard government's escape from the Iraq wheat scandal. Australian Journal of Political Science 43: 599-616.

McKenny, L. 2015. Local government chief forced to withdraw evidence. Sydney Morning Herald 2 August. URL: <http://www.smh.com.au/nsw/local-government-chief-forcedto-withdraw-evidence-20150731-giowi1.html>. Consulted 13 August 2016.

Mortensen, P. 2013. Public sector reform and blame avoidance effects. Journal of Public Policy 33(2):229-53.

Mortensen, P. 2016. Agencification and blame shifting: Evaluating a neglected side of public sector reforms. Public Administration. doi: 10.1111/padm.12243

Moynihan, D. 2012. Extra-network organizational reputation and blame avoidance in networks: The Hurricane Katrina example. Governance 25: 567-88.

NSW government. 2015a. Council boundary review. URL: <https://www.councilboundaryreview.nsw.gov.au/>. Consulted 9 February 2016. 
NSW government. 2015b. Stronger councils for Sydney and regional NSW. Media release 18 December. URL: <https://www.nsw.gov.au/media-releases-premier/stronger-councilssydney-and-regional-nsw>. Consulted 13 August 2016.

NSW government Department of Premier \& Cabinet. 2016. Application for access to government information. 2 February.

OLG [Office of Local Government]. 2015a. Fit for the Future. URL: <https://www.olg.nsw.gov.au/strengthening-local-government/local-governmentreform/fit-for-the-future>. Consulted 8 February 2016.

OLG [Office of Local Government]. 2015b. TCorp financial assessments. URL: <https://www.olg.nsw.gov.au/strengthening-local-government/local-governmentreform/TCORP-financial-assessments>. Consulted 8 December 2015.

Page, D. 2012a. Expert local government panel selected. Media release 17 April. Sydney: NSW government.

Page, D. 2012b. Independent review panel gets to work. Media release 18 March. Sydney: NSW government.

Page, D. 2013. Community's opportunity to comment on Independent Panel's report. Media release 24 April. Sydney: NSW government.

Robertson, J. 2016. Council amalgamation report 'awash with errors'. Sydney Morning Herald 25 January. URL: <http://www.smh.com.au/nsw/council-amalgamation-reportawash-with-errors-20160124-gmcsri.html>. Consulted 13 August 2016.

Sansom, G. 2015a. Consultation paper: Methodology for assessment of council Fit for the Future proposals. Sydney: Sansom.

Sansom, G. 2015b. The case for local government amalgamations in Sydney: Fact and fiction. Public Money and Management 35(1): 65-6. 
Sansom, M. 2015. NSW council sackings threat real: Local government expert. Government News 11 November. URL: <http://www.governmentnews.com.au/2015/11/nswcouncil-sackings-threat-real-local-government-expert/>. Consulted 13 August 2016.

State Parliament of NSW [Hansard]. 2015. Budget Estimates 2014-15 Supplementary Questions on Notice. URL:

<https://www.parliament.nsw.gov.au/committees/DBAssets/InquiryOther/Transcript/73 49/Answers\%20-\%20Supplementary\%20questions\%20\%20Local\%20Government.pdf>. Consulted 10 May 2016.

Steiner, R. 2003. The causes, spread and effects of intermunicipal cooperation and municipal mergers in Switzerland. Public Management Review 5: 551-71

TCorp. 2013. Financial sustainability of the New South Wales local government sector. Sydney: TCorp.

TCorp. 2015. Submission: Methodology for assessment of council Fit for the Future proposals. Sydney: TCorp

Toole, P. 2015a. Appointment of chief executive, Office of Local Government. Media release 28 April. Sydney: NSW government.

Toole, P. 2015b. IPART to play key role in assessing Fit for the Future council submissions. Media release 27 April. Sydney: NSW government.

Tversky, A. and Kahneman, D. 1992. Advances in prospect theory: Cumulative representation of uncertainty. Journal of Risk and Uncertainty 5: 297-323.

Weaver, K. 1986. The politics of blame avoidance. Journal of Public Policy 6: 371-98. 